\title{
Aplicação de entrevistas cognitivas para produzir versões brasileiras de instrumentos de avaliação da prática centrada na família
}

\section{Use of cognitive interviews to produce the Brazilian versions of instruments for the assessment of Family-Centered Practice}

\author{
Daniela Virginia Vaz', Dayana Karen Esteves da Silva ${ }^{2}$, \\ Débora Silva Campos², Ana Amélia Moraes Antunes, \\ Lívia de Castro Magalhães ${ }^{4}$, Sheyla Rossana Cavalcanti Furtado ${ }^{1}$
}

http://dx.doi.org/10.11606/issn.2238-6149.v29i1p41-49

\begin{abstract}
Vaz DV, Silva DKE, Campos DS, Antunes AAM, Magalhães LC, Furtado SRC. Aplicação de entrevistas cognitivas para produção de versões brasileiras de instrumentos de avaliação da prática centrada na família. Rev Ter Ocup Univ São Paulo. 2018 jan.-abr.;29(1):41-9.
\end{abstract}

RESUMO: A Prática Centrada na Família (PCF), considerada como best practice na assistência à criança, é um conjunto de atitudes e valores que reconhece a família como centro do cuidado. A MPOC-20 e MPOC-SP são questionários que avaliam a percepção dos cuidadores e dos profissionais de saúde, acerca da PCF. Este trabalho descreve o processo de tradução e adaptação transcultural dos instrumentos para o português brasileiro. A tradução deve garantir total compreensão das questões pelos entrevistados, assim, para avaliar essa compreensão utilizamos como ferramenta a entrevista cognitiva. Foram identificados problemas de compreensão em ambos os questionários, e foram feitos ajustes para solucioná-los. O uso da entrevista cognitiva foi fundamental para o processo de tradução e adaptação transcultural dos questionários.

DESCRITORES: Entrevista cognitiva; MPOC-20; MPOC-SP; Prática Centrada na Família.
Vaz DV, Silva DKE, Campos DS, Antunes AAM, Magalhães LC, Furtado SRC. Use of cognitive interviews to produce the Brazilian versions of instruments for the assessment of Family-Centered Practice. Rev Ter Ocup Univ São Paulo. 2018 Jan.-Apr.;29(1):41-9.

ABSTRACT: Family-Centered Practice (FCP), considered the best practice in childcare, is a set of attitudes and values for clinical practice that recognize the child's family as the center of care. MPOC-20 and MPOC-SP are questionnaires that evaluate the perception of caregivers and health professionals about FCP in a given service. This study describes part of the crosscultural translation and adaptation process of the instruments into Brazilian Portuguese. The translation should guarantee a total understanding of the questions by the interviewees. To evaluate such understanding, we used the method of cognitive interviews. Problems of understanding were identified in both questionnaires and adjustments were made to remove them. The use of the cognitive interviews was essential for the translation and cultural adaptation of the questionnaires.

KEYWORDS: Cognitive interview; Family-Centered Practice; MPOC-20; MPOC-SP.

Este trabalho é parte da monografia 'Entrevista cognitiva: ajustes das versões brasileiras da MPOC-20 e MPOC-SP', do Curso de Graduação em Fisioterapia da Universidade Federal de Minas Gerais.

1. Professora do Departamento de Fisioterapia, Universidade Federal de Minas Gerais (UFMG), Belo Horizonte, MG, BR. E-mail: danielavvaz@gmail.com; sheylaufmg@yahoo.com.br

2. Estudante de Graduação em Fisioterapia, Universidade Federal de Minas Gerais (UFMG), Belo Horizonte, MG, BR. E-mail: dayana. kasilva@hotmail.com; deboracampos94@hotmail.com

3. Fisioterapeuta da Rede SARAH de Hospitais de Reabilitação e Pós-Graduanda no programa de Ciências da Reabilitação da Universidade Federal de Minas Gerais (UFMG), Belo Horizonte, MG, BR. E-mail: antunesanaamelia@gmail.com

4. Professora do Departamento de Terapia Ocupacional, Universidade Federal de Minas Gerais (UFMG), Belo Horizonte, MG, BR. E-mail: liviacmag@gmail.com

Endereço para correspondência: Daniela Virginia Vaz. Departamento de Fisioterapia, Universidade Federal de Minas Gerais. Avenida Antônio Carlos, 6627, Campus Pampulha. Belo Horizonte, MG, Brasil. CEP: 31270-901. E-mail: danielavvaz@gmail.com 


\section{INTRODUÇÃO}

fisioterapia e a terapia ocupacional, como
profissões clínicas, são constantemente
desafiadas a garantir qualidade no atendimento. Profissionais de reabilitação, pacientes e famílias almejam resultados terapêuticos que satisfaçam as demandas e necessidades específicas de cada uma das partes envolvidas. Modelos tradicionais de prática se baseiam em uma assistência verticalizada em que o terapeuta é a autoridade que determina o que deve ser feito na terapia. No entanto, atualmente fisioterapeutas e terapeutas ocupacionais têm se aproximado de um modelo mais horizontal em que as decisões terapêuticas e responsabilidades são compartilhadas com as famílias, respaldados pelos princípios da Prática Centrada na Família ${ }^{1}$.

A Prática Centrada na Família (PCF) é um conjunto de atitudes e valores que orientam o cuidado oferecido a crianças com deficiências. A PCF reconhece que a família da criança tem experiências únicas e conhecimento privilegiado sobre as suas necessidades e habilidades particulares. Por isso, nesta abordagem, a família tem sua perspectiva valorizada e toma decisões sobre os cuidados prestados em parceria com os prestadores de serviço. Serviços centrados na família têm como premissa colaborar e compartilhar informações, de maneira individualizada e flexível. Além disso a PCF ressalta a importância de dar atenção não só para a criança com deficiência, mas a todos os membros da unidade familiar, pois a saúde e bem-estar da família refletem na evolução ou desenvolvimento da criança ${ }^{2-6}$.

Profissionais que seguem essa filosofia, buscam educar as famílias sobre a importância de sua participação ativa no tratamento, pois os ganhos proporcionados com a terapia são substancialmente maiores quando o objetivo está centrado nas necessidades apontadas pela família $^{6}$. A PCF traz como vantagens a satisfação dos pais, redução de estresse, maior motivação e adesão aos programas de terapia ${ }^{6}$. A autonomia e o exercício de escolha são a base da PCF. Tais princípios contribuem para aumentar a eficácia da reabilitação, além de evidenciar o respeito a direitos fundamentais daqueles que recebem cuidados de saúde ${ }^{7}$, que é essencial em qualquer prática terapêutica.

A avaliação de um serviço quanto ao grau de centralidade na família permite o reconhecimento de quais melhorias são necessárias ${ }^{8}$. Nesta avaliação, o uso de ferramentas sistematizadas ao invés de avaliações informais é mais confiável. Atualmente já existem medidas, como a Measure of Process of Care (MPOC), que podem ser usadas para avaliar os serviços de maneira sistematizada. A MPOC é constituída por questionários padronizados, desenvolvidos originalmente no Canadá para medir a implementação da prática centrada na família em serviços para crianças com problemas crônicos de desenvolvimento ${ }^{8}$.

Entre as versões das MPOC, destacam-se a MPOC56, a MPOC-20 e a MPOC-SP (Service Providers). A MPOC-56 é um questionário sobre as percepções dos pais acerca da qualidade da prestação de serviços à criança ${ }^{9,10}$, que tem uma versão curta, a MPOC-20. Já a MPOC-SP é voltada para que os profissionais envolvidos no cuidado aos pacientes expressem sua percepção sobre o serviço ${ }^{8}$. As três medidas, MPOC-SP, 56 e 20, consistem em questionários padronizados que podem ser auto aplicados. A MPOC-56 demonstra alta consistência interna (alfa de Cronbach entre 0,81 e 0,96), confiabilidade testereteste (ICC entre 0,78 a 0,88 ) e validade de constructo ${ }^{8}$. A versão MPOC-20 também tem boa validade e boa consistência interna (alfa de Cronbach entre 0,83 a 0,90$)^{11}$. A MPOC-SP tem propriedades psicométricas satisfatórias, com boa consistência interna (alfa de Cronbach entre de 0,76 a 0,88 ) e boa confiabilidade teste-reteste (ICC entre de 0,79 a 0,99$)^{12}$. Os questionários permitem o cálculo de escores que refletem o quanto determinado serviço é centrado na criança e sua família.

É importante avaliar em que extensão cada serviço adota os princípios da prática centrada na família para aprimorar o processo de reabilitação. As percepções dos pais e profissionais sobre áreas específicas do atendimento que requerem melhorias são fundamentais para que a prática clínica seja de fato centrada na família. Assim, o uso das escalas padronizadas como a MPOC poderia contribuir para a melhoria de serviços de fisioterapia e terapia ocupacional no nosso país, sendo importante traduzir e adequar estas escalas para a realidade brasileira.

Para a produção das versões brasileiras das escalas, é necessário seguir procedimentos rigorosos de tradução transcultural, utilizados internacionalmente, que incluem realizar a tradução, retro-tradução e ajustes contextuais para produção da versão em português Brasileiro dos questionários, originalmente disponíveis no idioma inglês ${ }^{12}$. Como a MPOC foi criada no formato de questionários auto-aplicados, deve-se também analisar se os entrevistados compreendem seus enunciados e opções de repostas, assim como o seu conteúdo e propósito ${ }^{13}$. Um recurso recomendado para verificar a compreensão de cada item do instrumento 
Vaz DV, et al. Aplicação de entrevistas cognitivas para produção de versões brasileiras. Rev Ter Ocup Univ São Paulo. 2018 jan/abr.;29(1):41-9.

pela população alvo de cada questionário é o uso de 'entrevistas cognitivas'. As entrevistas cognitivas constituem um método para investigar se os enunciados e opções de respostas às questões de um questionário são interpretadas conforme o esperado ${ }^{14}$, o que permite determinar se há necessidade de ajustes na versão traduzida para adequação ao contexto cultural do país para o qual se propõe a tradução.

Neste estudo foi investigada a compreensão da tradução Brasileira da MPOC-20 e MPOC-SP, por parte de pais/cuidadores e profissionais envolvidos na reabilitação infantil, por meio do procedimento de entrevista cognitiva. Os resultados dessa análise permitirão fazer ajustes na versão brasileira dos dois questionários da MPOC, para que possamos contar com instrumentos válidos e confiáveis para avaliar a qualidade da assistência na prática clínica e na pesquisa em reabilitação infantil no Brasil.

\section{PROCEDIMENTOS METODOLÓGICOS}

Neste estudo foram usadas traduções preliminares da MPOC-20 e MPOC-SP, obtidas como descrito a seguir. A primeira etapa do processo de produção destas versões envolveu obter a permissão dos autores originais, da fundação CanChild, para a tradução dos instrumentos. Em seguida, conforme procedimentos recomendados para tradução transcultural de questionários ${ }^{13}$, foram realizadas traduções independentes por dois especialistas (uma professora universitária e uma fisioterapeuta). Em seguida, foi formado painel de 'experts' composto por três professoras universitárias, duas fisioterapeutas e duas estudantes de graduação em fisioterapia. O painel comparou as duas traduções a fim de identificar diferenças e discordâncias e então produzir uma versão única, a qual foi submetida a tradução reversa para o idioma de origem do questionário. Assim como na tradução, a retro tradução foi feita por dois tradutores independentes, um tradutor norte americano e um britânico. Um segundo painel, composto por uma fisioterapeuta e duas professoras universitárias, comparou as traduções entre si, com a versão brasileira e com os questionários originais em inglês, produziu uma versão retro-traduzida unificada e realizou ajustes finais nas traduções brasileiras da MPOC-20 e MPOC-SP. Depois da retrotradução unificada e a versão final em português terem sido avaliadas e aprovadas pela CanChild, foi verificado, por meio do procedimento de entrevista cognitiva, se os questionários traduzidos eram bem compreendidos por pais/cuidadores e por profissionais brasileiros. As etapas do processo encontram-se resumidas na Figura 1.

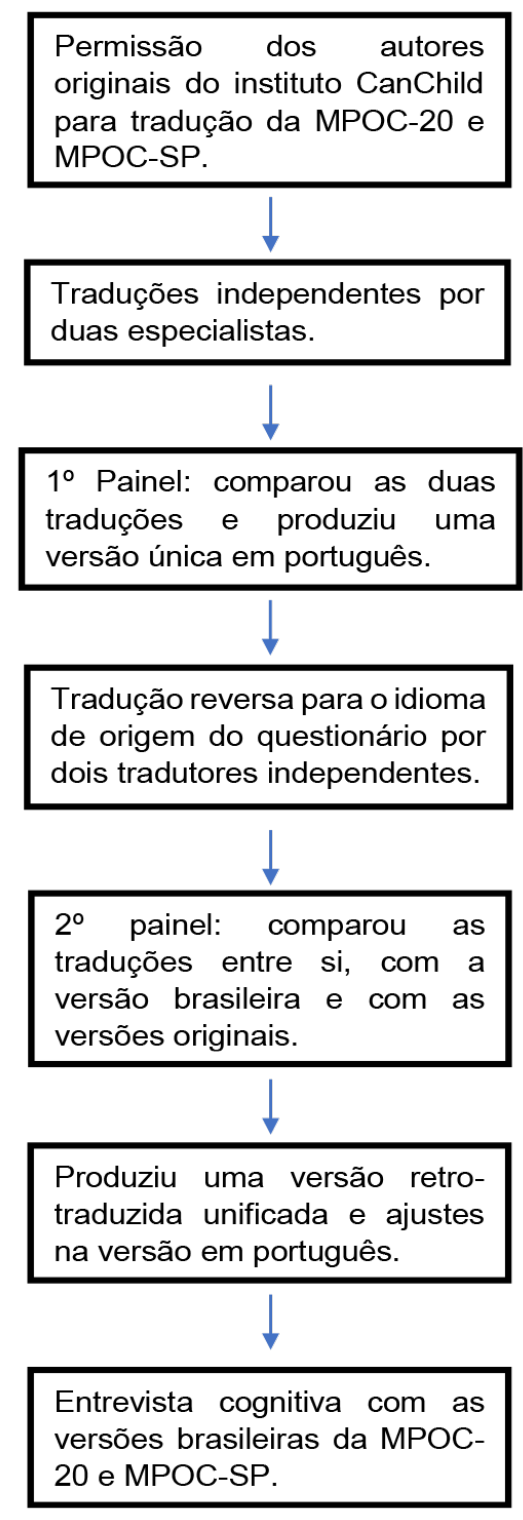

Figura 1 - Diagrama das etapas de produção das versões brasileiras da MPOC-20 e MPOC-SP

\section{Participantes}

Foi constituída uma amostra de conveniência com nove pais/cuidadores e nove profissionais recrutados no serviço de reabilitação do Ambulatório Bias Fortes do Hospital das Clínicas da UFMG. Para a MPOC-20, foram realizadas entrevistas com pais/cuidadores de crianças com problemas crônicos de desenvolvimento e, para a 
MPOC-SP, foram entrevistados profissionais envolvidos na reabilitação infantil. Todos os participantes assinaram Termo de Consentimento Livre e Esclarecido específico para cada versão aplicada.

A previsão de recrutamento foi de no mínimo nove participantes para avaliar cada questionário. $\mathrm{O}$ tamanho da amostra foi definido baseado nos estudos que indicam que pelo menos duas a três entrevistas em três rodadas sejam suficientes para revelar os problemas mais críticos do questionário ${ }^{13}$. Para a entrevista cognitiva da versão MPOC-20 foram incluídos pais/cuidadores de crianças em acompanhamento há um ano ou mais no serviço, sendo que foram excluídos aqueles que não compareceram a mais de 50\% dos atendimentos oferecidos. Para a MPOCSP foram incluídos profissionais que atuavam diretamente na reabilitação infantil no último ano, sendo excluídos profissionais que atuavam na reabilitação infantil por tempo inferior a 60 dias no último ano.

\section{Procedimentos}

As entrevistas cognitivas podem ser feitas por meio de dois processos, denominados 1) pensamento em voz alta e 2) sondagem de seguimento ${ }^{14}$. O primeiro consiste em incentivar os participantes a responderem as perguntas do questionário verbalizando seus pensamentos. $\mathrm{O}$ segundo consiste em perguntas diretas e explícitas realizadas pelo entrevistador. Ambos os procedimentos podem ser utilizados conjuntamente, uma vez que se encaixam naturalmente e trazem importantes informações acerca da compreensão do entrevistado sobre os itens dos questionários ${ }^{14}$.

As entrevistas cognitivas por meio de pensamento em voz alta e sondagem de seguimento foram realizadas no período de julho e agosto de 2017 e foram registradas em gravador de voz de um aparelho celular. Durante a entrevista cognitiva os itens que considerados difíceis ou mal interpretados pelos entrevistados foram assinalados pelas entrevistadoras. Os itens dos questionários selecionados para ajustes foram aqueles em que dois ou mais cuidadores e pelo menos um profissional apresentaram dificuldade de compreensão, para a MPOC-20 e MPOC-SP, respectivamente. Quando o entrevistado solicitou a repetição do enunciado, das opções de respostas e/ou fornecimento de exemplo, as entrevistadoras consideraram que havia dificuldade de compreensão.

Tanto para a versão preliminar brasileira da MPOC-20 quanto da MPOC-SP, as entrevistas cognitivas foram planejadas e realizadas em três etapas da seguinte maneira: inicialmente foram feitas três entrevistas com três participantes diferentes de cada grupo e, com base nos dados das entrevistas de cada grupo, foram feitos os ajustes necessários em itens específicos, a fim de corrigir os problemas que surgiram. Esses ajustes foram feitos por uma fisioterapeuta e duas alunas de graduação em fisioterapia. Adaptamos o enunciado das questões dos questionários cujas respostas das entrevistas indicaram dificuldade de compreensão. Feitas essas correções, partimos para a segunda rodada de entrevistas, na qual o mesmo processo foi realizado. Foi feita, ainda, uma terceira rodada de entrevistas, aplicando-se os questionários com as adaptações realizadas na segunda rodada. Após a terceira rodada de entrevistas, ficou evidente que ajustes adicionais não eram mais necessários.

As entrevistas foram iniciadas com o método de pensamento em voz alta, para o qual os participantes receberam instruções padronizadas do tipo: "Por favor, me diga o que você pensou para responder essa pergunta" e "Pense na sua resposta em voz alta". Neste procedimento, o investigador não influenciou as respostas do participante.

Em seguida, foi feita sondagem das respostas, para estimular que os entrevistados se expressassem de forma mais clara e completa. As pesquisadoras perguntaram aos entrevistados: "Você pode me dizer com as suas palavras o que esta questão está perguntando?" ou "Me diga como você compreendeu/entendeu esta pergunta". O sentido atribuído pelos entrevistados aos enunciados das questões dos instrumentos foi comparado pelas pesquisadoras com o sentido pretendido na versão original em inglês. As sondagens permitiram a identificação de enunciados cuja tradução acarretou em dificuldades de compreensão.

\section{Análise dos Dados}

Após cada rodada de entrevistas, um painel de especialistas, composto por duas graduandas do curso de fisioterapia e uma fisioterapeuta responsável técnica de um serviço de reabilitação, analisou os arquivos de voz para identificar as razões expressas pelos entrevistados para as dificuldades de compreensão. Com base nesta análise, o painel fez ajustes na versão em português das MPOC, visando eliminar as dificuldades de interpretação na rodada seguinte de entrevistas.

\section{RESULTADOS}

Foram realizadas três rodadas de entrevistas cognitivas para cada um dos questionários, cada rodada envolveu três entrevistados, somando nove cuidadores para a MPOC-20 e nove profissionais para a MPOC-SP, o que totalizou 18 participantes. Nas entrevistas cognitivas 
com a MPOC-20, a maioria dos participantes eram mães, com exceção de um pai e uma avó, que também fizeram parte do estudo. A média de idade dos cuidadores foi de 35,7 anos, destes, cinco tinham ensino médio completo, um ensino médio incompleto e três o ensino fundamental incompleto. O tempo de assistência que as crianças receberam variou de 1 ano e 4 meses a 7 anos. Já para a MPOC-SP, dos nove profissionais entrevistados, oito foram do sexo feminino e um do sexo masculino, a média de idade dos profissionais foi de 32,6 anos. Além disso, dois possuíam pós-graduação e o tempo de atuação na área infantil variou de um ano e dois meses a 22 anos.

Para a MPOC-20, considerando que houve dez solicitações para fornecimento de exemplo, oito pedidos para repetição de enunciado e duas solicitações para repetição das opções de respostas, foram ajustadas oito questões. A principal dificuldade apresentada pelos entrevistados foi a compreensão de termos ou palavras das questões, como: "competente", "longo período de tempo", "tempo de conversa", "mesma direção", "de pessoa para pessoa" e "formato". Outras duas dificuldades se manifestaram pelo não entendimento de que havia duas perguntas em uma mesma questão (item 4) e a não compreensão de um exemplo (item 11). Para todas as dificuldades foram feitos ajustes na redação das questões para torná-las mais inteligíveis e precisas. Todos os ajustes e detalhamento dos problemas identificados estão descritos na Tabela 1.

Tabela 1 - Sínteses das Entrevistas Cognitivas feitas com pais/cuidadores sobre a compreensão dos itens da MPOC-20

\begin{tabular}{|c|c|c|c|c|c|}
\hline Questão & Rodada 1 & Rodada 2 & Rodada 3 & $\begin{array}{l}\text { Detalhamento do } \\
\text { problema encontrado }\end{array}$ & Redação final da questão \\
\hline $\begin{array}{l}\text { 1. ...ajudaram você a se sentir } \\
\text { competente como mãe ou pai? }\end{array}$ & & $\begin{array}{l}\mathrm{RE} \\
\mathrm{EX}\end{array}$ & & $\begin{array}{l}\text { Dificuldade de compreender } \\
\text { "competente", mesmo com } \\
\text { uso de sinônimos. }\end{array}$ & $\begin{array}{l}\text {... ajudaram você a se sentir } \\
\text { competente como mãe ou pai (por } \\
\text { exemplo fizeram elogios e deram } \\
\text { incentivos nos atendimentos)? }\end{array}$ \\
\hline $\begin{array}{l}\text { 4. ...deixaram você escolher } \\
\text { quando receber informação e o } \\
\text { tipo de informação que queria? }\end{array}$ & $\begin{array}{l}\mathrm{RE} \\
\mathrm{EX} \\
\mathrm{RR}\end{array}$ & $\begin{array}{l}\mathrm{RE} \\
\mathrm{EX}\end{array}$ & & $\begin{array}{l}\text { Dificuldade em entender } \\
\text { que havia duas perguntas } \\
\text { na mesma questão. } \\
\text { Desconsideração do termo } \\
\text { "quando" e resposta baseada } \\
\text { apenas no "tipo". }\end{array}$ & $\begin{array}{l}\text {... deixaram você escolher o } \\
\text { momento de receber informação e c } \\
\text { tipo de informação de queria? (por } \\
\text { exemplo, você pôde fazer perguntas } \\
\text { no momento que você queria)? }\end{array}$ \\
\hline $\begin{array}{l}\text { 6. ...garantiram que pelo } \\
\text { menos um profissional da } \\
\text { equipe trabalhou com você } \\
\text { e sua família por um longo } \\
\text { período de tempo? }\end{array}$ & $\begin{array}{l}\mathrm{RE} \\
\mathrm{EX}\end{array}$ & $\begin{array}{l}\mathrm{RE} \\
\mathrm{EX}\end{array}$ & & $\begin{array}{l}\text { Dificuldade em quantificar } \\
\text { "longo período de tempo", } \\
\text { além de não compreenderem } \\
\text { o objetivo da questão. }\end{array}$ & $\begin{array}{l}\text {...garantiram que pelo menos um } \\
\text { profissional da equipe trabalhou } \\
\text { com você e sua família ao longo } \\
\text { deste ano (por exemplo, você } \\
\text { tem uma pessoa de referência na } \\
\text { equipe)? }\end{array}$ \\
\hline $\begin{array}{l}\text { 9. ...deram tempo suficiente } \\
\text { para conversar, para você não } \\
\text { se sentir apressado? }\end{array}$ & EX & & & $\begin{array}{l}\text { Dificuldade em entender } \\
\text { quando seria o "tempo de } \\
\text { conversa". }\end{array}$ & $\begin{array}{l}\text {...deram tempo suficiente para } \\
\text { conversar, para você não se sentir } \\
\text { apressado (por exemplo, você pôde } \\
\text { tirar a suas dúvidas com calma } \\
\text { durante os atendimentos)? }\end{array}$ \\
\hline $\begin{array}{l}\text { 10. ...planejaram juntos de } \\
\text { forma que todos estivessem } \\
\text { trabalhando na mesma direção? }\end{array}$ & & & $\begin{array}{l}\mathrm{RE} \\
\mathrm{EX}\end{array}$ & $\begin{array}{l}\text { Dificuldade com o termo } \\
\text { "mesma direção". }\end{array}$ & $\begin{array}{l}\text {... planejaram juntos de forma que } \\
\text { todos estivessem trabalhando com c } \\
\text { mesmo objetivo? }\end{array}$ \\
\hline $\begin{array}{l}\text { 11. ...trataram você de igual } \\
\text { para igual, ao invés de tratar } \\
\text { apenas como pai ou mãe de } \\
\text { um paciente (por exemplo, não } \\
\text { te chamaram apenas de "pai" } \\
\text { ou "mãe")? }\end{array}$ & $\begin{array}{l}\mathrm{RE} \\
\mathrm{EX}\end{array}$ & & & $\begin{array}{l}\text { Dificuldade com o } \\
\text { exemplo da questão e não } \\
\text { compreensão do que seria } \\
\text { chamá-los apenas de pai ou } \\
\text { mãe. }\end{array}$ & $\begin{array}{l}\text {... trataram você de igual para igual, } \\
\text { ao invés de tratar apenas como pai ou } \\
\text { mãe de um paciente (por exemplo, te } \\
\text { chamaram pelo seu nome e sabiam o } \\
\text { nome do seu filho)? }\end{array}$ \\
\hline
\end{tabular}


Vaz DV, et al. Aplicação de entrevistas cognitivas para produção de versões brasileiras. Rev Ter Ocup Univ São Paulo. 2018 jan/abr:;29(1):41-9.

Tabela 1 - Sínteses das Entrevistas Cognitivas feitas com pais/cuidadores sobre a compreensão dos itens da MPOC-20

\begin{tabular}{|c|c|c|c|c|c|}
\hline Questão & Rodada 1 & Rodada 2 & Rodada 3 & $\begin{array}{l}\text { Detalhamento do } \\
\text { problema encontrado }\end{array}$ & Redação final da questão \\
\hline $\begin{array}{l}\text { 12. ...deram para você } \\
\text { informação que não variou de } \\
\text { pessoa para pessoa? }\end{array}$ & EX & $\mathrm{RR}$ & & $\begin{array}{l}\text { Dificuldade de compreender } \\
\text { "de pessoa para pessoa" } \\
\text { e não entendimento do } \\
\text { objetivo da questão. }\end{array}$ & $\begin{array}{l}\text {...deram para você informação } \\
\text { que não mudou de um profissional } \\
\text { para o outro (por exemplo, todos } \\
\text { os profissionais que acompanham } \\
\text { a sua criança te deram a mesma } \\
\text { informação)? }\end{array}$ \\
\hline $\begin{array}{l}\text { 19. ...tinham informação } \\
\text { disponível para você me vários } \\
\text { formatos, como cartilha, kit, } \\
\text { folheto, vídeo, etc? }\end{array}$ & $\begin{array}{l}\mathrm{RE} \\
\mathrm{EX}\end{array}$ & & & $\begin{array}{l}\text { Dificuldade em compreender } \\
\text { "formato". }\end{array}$ & $\begin{array}{l}\text {... tinham informação disponível } \\
\text { para você em forma de cartilha, kit, } \\
\text { folheto, vídeo, etc? }\end{array}$ \\
\hline
\end{tabular}

Legenda: RR: Solicitada repetição das opções de resposta; RE: Solicitada repetição do enunciado; EX: Solicitado fornecimento de exemplos.

Para a MPOC-SP foram feitas oito solicitações de exemplos, cinco pedidos de repetição do enunciado e duas solicitações para repetição das opções de respostas, indicando que oito questões necessitavam de ajustes. As dificuldades mais comuns foram relacionadas a abrangência de termos, ou seja, os profissionais não compreendiam o que os termos "programa domiciliar", "prestadores de serviço", "família inteira" e "gerais" abarcavam. Outros problemas encontrados foram associados a compreensão de exemplos, palavras e objetivo da questão. A descrição das dificuldades encontradas e respectivos ajustes encontra-se na Tabela 2.

Tabela 2 - Síntese das Entrevistas Cognitivas realizadas com profissionais acerca da qualidade dos itens da MPOC-SP

\begin{tabular}{|c|c|c|c|c|c|}
\hline Questão & Rodada 1 & Rodada 2 & Rodada 3 & $\begin{array}{l}\text { Detalhamento o } \\
\text { problema encontrado }\end{array}$ & Redação final da questão \\
\hline $\begin{array}{l}2 \text {...ofereceu aos pais e } \\
\text { crianças um retorno positivo } \\
\text { ou encorajamento (ex.: na } \\
\text { realização de um programa } \\
\text { domiciliar)? }\end{array}$ & $\begin{array}{l}\text { RR } \\
\text { RE } \\
\text { EX }\end{array}$ & & & $\begin{array}{l}\text { Dificuldade em entender } \\
\text { a abrangência de } \\
\text { "programa domiciliar". }\end{array}$ & $\begin{array}{l}\text {...ofereceu aos pais e crianças um } \\
\text { retorno positivo ou encorajamento } \\
\text { (ex. na realização de orientação } \\
\text { domiciliar)? }\end{array}$ \\
\hline $\begin{array}{l}4 \text {...discutiu expectativas } \\
\text { para cada criança com outros } \\
\text { prestadores de serviço, para } \\
\text { garantir consistência de } \\
\text { pensamentos e ações? }\end{array}$ & & & EX & $\begin{array}{l}\text { Dificuldade em } \\
\text { entender a abrangência } \\
\text { de "prestadores de } \\
\text { serviço". }\end{array}$ & $\begin{array}{l}\text {... discutiu expectativas para cada } \\
\text { criança com outros prestadores } \\
\text { de serviço (seja da sua categoria } \\
\text { profissional e não), para garantir } \\
\text { consistência de pensamentos e ações? }\end{array}$ \\
\hline $\begin{array}{l}7 \text {... Confiou nos pais como os } \\
\text { 'especialistas' em sua criança? }\end{array}$ & $\begin{array}{l}\mathrm{RE} \\
\mathrm{EX}\end{array}$ & & & $\begin{array}{l}\text { Dificuldade de } \\
\text { compreender a quem } \\
\text { se referia o termo } \\
\text { "especialistas". }\end{array}$ & $\begin{array}{l}\text {... Confiou nos pais como os } \\
\text { "especialistas" em sua criança? } \\
\text { Ou seja, entende que os pais são } \\
\text { as pessoas que mais conhecem a } \\
\text { criança? }\end{array}$ \\
\hline $\begin{array}{l}11 \text {... deixou os pais } \\
\text { escolherem quando receber } \\
\text { informação e que tipo de } \\
\text { informação que eles queriam? }\end{array}$ & & $\begin{array}{l}\mathrm{RE} \\
\mathrm{EX}\end{array}$ & & $\begin{array}{l}\text { Dificuldade em entender } \\
\text { o objetivo da questão. }\end{array}$ & $\begin{array}{l}\text {... deixou os pais escolherem quando } \\
\text { receber informação e que tipo de } \\
\text { informação eles queriam? (por } \\
\text { exemplo, deu oportunidade para } \\
\text { tirarem as dúvidas de interesse deles } \\
\text { e no momento que eles queriam)? }\end{array}$ \\
\hline
\end{tabular}


Vaz DV, et al. Aplicação de entrevistas cognitivas para produção de versões brasileiras. Rev Ter Ocup Univ São Paulo. 2018 jan/abr.;29(1):41-9.

Tabela 2 - Síntese das Entrevistas Cognitivas realizadas com profissionais acerca da qualidade dos itens da MPOC-SP

\begin{tabular}{|c|c|c|c|c|c|}
\hline Questão & Rodada 1 & Rodada 2 & Rodada 3 & $\begin{array}{l}\text { Detalhamento o } \\
\text { problema encontrado }\end{array}$ & Redação final da questão \\
\hline $\begin{array}{l}12 \text {...ajudou cada família a } \\
\text { manter uma relação estável } \\
\text { com pelo menos um prestador } \\
\text { do serviço que trabalhe com a } \\
\text { criança e os pais por um longo } \\
\text { período de tempo? }\end{array}$ & & $\begin{array}{l}\mathrm{RE} \\
\mathrm{EX}\end{array}$ & & $\begin{array}{l}\text { Dificuldade em } \\
\text { compreender se pelo } \\
\text { menos um membro da } \\
\text { equipe que acompanhou } \\
\text { a criança durante um } \\
\text { longo período de tempo. }\end{array}$ & $\begin{array}{l}\text {...ajudou cada família a manter um } \\
\text { vínculo estável com pelo menos um } \\
\text { prestador do serviço que acompanhe } \\
\text { a criança e os pais por um longo } \\
\text { período de tempo? }\end{array}$ \\
\hline $\begin{array}{l}18 \text {... tratou pais de igual para } \\
\text { igual, e não apenas a mãe ou } \\
\text { pai de um paciente (ex. não se } \\
\text { referindo a eles como "Mãe" } \\
\text { ou "Pai")? }\end{array}$ & & $\begin{array}{l}\text { EX } \\
\text { RR }\end{array}$ & & $\begin{array}{l}\text { Dificuldade em } \\
\text { compreender o exemplo } \\
\text { da questão. }\end{array}$ & $\begin{array}{l}\text {... tratou pais de igual para igual, e } \\
\text { não apenas de maneira genérica (ex. } \\
\text { não se referindo a eles como "Mãe" } \\
\text { ou "Pai" e sim chamando-os pelo } \\
\text { próprio nome)? }\end{array}$ \\
\hline $\begin{array}{l}26 \text {... deu oportunidade } \\
\text { para a família inteira, } \\
\text { incluindo irmãos, para obter } \\
\text { informação? }\end{array}$ & & EX & & $\begin{array}{l}\text { Dificuldade em } \\
\text { entender a abrangência } \\
\text { de "família inteira" e } \\
\text { dúvida sobre quem seria } \\
\text { a informação fornecida. }\end{array}$ & $\begin{array}{l}\text {... deu oportunidade para a família } \\
\text { inteira (todos que convivem } \\
\text { diretamente com a criança) incluindo } \\
\text { irmãos, para obter informação sobre } \\
\text { a criança? }\end{array}$ \\
\hline $\begin{array}{l}27 \text {... tiveram informações } \\
\text { gerais disponíveis sobre } \\
\text { diferentes preocupações } \\
\text { (ex. custos financeiros ou } \\
\text { assistência, aconselhamento } \\
\text { genético, descanso, namoro e } \\
\text { sexualidade)? }\end{array}$ & & $\begin{array}{l}\mathrm{RE} \\
\mathrm{EX}\end{array}$ & & $\begin{array}{l}\text { O termo "tiveram" } \\
\text { gerou dúvida, uma vez } \\
\text { que os profissionais } \\
\text { entenderam que a } \\
\text { questão buscava saber } \\
\text { se eles (profissionais) } \\
\text { tiveram acesso as } \\
\text { informações e não } \\
\text { a família. Dúvidas } \\
\text { sobre a abrangência do } \\
\text { termo "gerais" e dos } \\
\text { exemplos. }\end{array}$ & $\begin{array}{l}\text {... disponibilizou informações } \\
\text { abrangentes sobre diferentes } \\
\text { preocupações relacionadas com a } \\
\text { realidade da criança (por exemplo } \\
\text { custos financeiros ou assistência, } \\
\text { aconselhamento genético, descanso, } \\
\text { namoro e sexualidade)? }\end{array}$ \\
\hline
\end{tabular}

Legenda: RR: Solicitada repetição das opções de resposta; RE: Solicitada repetição do enunciado; EX: Solicitado fornecimento de exemplos.

\section{DISCUSSÃO}

A tradução e a adaptação transcultural de questionários envolve desafios complexos no sentido de se alcançar uma redação consistente com o original e mais próxima possível da realidade cultural de um país. Para tanto, é fundamental solucionar os problemas de linguagem encontrados nos questionários traduzidos para tornar as perguntas mais precisas e claras, conforme o instrumento original. A entrevista cognitiva como recurso para identificação dos problemas de compreensão se mostrou útil, tornando possível a correção de problemas na MPOC-20 e MPOC-SP.

$\mathrm{Na}$ análise dos dados das entrevistas, ficou evidente a similaridade entre as dificuldades relacionadas as questões da MPOC-20 e MPOC-SP. As questões mais difíceis de compreender em um questionário foram correspondentes às mais difíceis no outro, já que os dois 
questionários têm questões similares. Isso indica que a tradução bem como a adaptação transcultural realizada pelo painel de experts para tais questões foi consistente entre os itens correspondentes de cada instrumento, mas não foi suficiente para tornar o item claro para os entrevistados, fossem eles pais ou profissionais. As dificuldades encontradas indicam a importância do processo de verificação por meio de entrevistas cognitivas, para garantir a adequação da versão local de instrumentos de origem estrangeira.

Além das dificuldades gerais com o estilo linguístico das perguntas, é possível que algumas falhas na compreensão de termos da MPOC-20 estejam associadas a falta de familiaridade dos cuidadores com significado de termos técnicos, comuns entre profissionais, mas não entre usuários de serviços de saúde. O nível de escolaridade dos entrevistados também foi relevante, já que os entrevistados com menor grau de escolaridade foram os que mais apresentaram dificuldades. Uma vez que grande parcela da população brasileira ainda possui baixa escolaridade, a investigação sistemática da compreensão feita neste estudo resultou na adaptação dos questionários de acordo com a realidade do país, abrangendo assim um maior número de usuários que poderão avaliar a qualidade dos serviços através da MPOC-20. Em relação a MPOC-SP, aparentemente as dificuldades foram relacionadas a pouca clareza de alguns termos nas questões, o que gerou dúvidas sobre a sua abrangência. Foi nítida a melhora da compreensão a cada rodada de entrevistas, após a realização de ajustes.

Considerando que o contexto sócio político influencia no comportamento de empoderar-se em relação participação ativa nas decisões em de serviços de saúde ${ }^{15} \mathrm{e}$ que o país de origem do questionário tem importantes diferenças em relação a realidade brasileira, o painel de especialistas cogitou a possibilidade de dificuldades de entendimento e falta de pertinência dos objetivos dos questionários. Entretanto, durante as entrevistas, os pais/ cuidadores e profissionais entenderam que o questionário

\section{REFERÊNCIAS}

1. Epstein RM, Street RL. The values and value of patientcentered care. Ann Fam Med. $2011 ; 9$ (2):100-3. doi: 10.1370/afm. 1239

2. Law M, Rosenbaum P, King G. Family-centred service sheets: 18 educational materials designed for parents, service providers, and organizations. CanChild Centre Childhood Disabil Res. 2003;29(5):357-66. tratava de parceria, fornecimento de informações e respeito as famílias, sendo as dúvidas relacionadas apenas à formulação linguística dos enunciados em si. Além disso, os entrevistados demostraram apreciar os conteúdos dos questionários MPOC, fazendo elogios e comentários sobre a importância destes assuntos para qualidade da assistência.

Este estudo teve limitações relacionadas a fatores externos aos instrumentos que possivelmente influenciaram as respostas. A presença da criança durante as entrevistas com os pais/cuidadores interferiu na discussão dos itens de maior dificuldade, já que o cuidador precisava dividir a atenção entre o questionário e a vigilância da criança. Além disso, de maneira geral, os profissionais, devido a seus compromissos de trabalho, tiveram pouco tempo disponível para participar do estudo, mostrando-se apressados para discutir as questões. Assim, idealmente as entrevistas com a MPOC-20 e MPOC-SP, em situações de uso clínico, devem ser feitas em horários previamente agendados, por de cerca 20 minutos dedicados somente para esta atividade. Apesar destas limitações, todas as entrevistas cumpriram o propósito do estudo, que foi de identificar itens complexos e corrigi-los, para possibilitar melhor compreensão dos questionários.

\section{CONCLUSÃO}

A entrevista cognitiva como ferramenta de análise da compreensão dos questionários MPOC-20 e MPOC-SP se mostrou como recurso indispensável, uma vez que sua utilização foi fundamental para localizar problemas e possibilitar o ajuste das questões, melhorando sua compreensão dentro do contexto cultural do país. Conhecer a interpretação de cada questão, por parte dos entrevistados, e ajustá-las, foi importante para garantir que os questionários recém traduzidos estejam de fato se referindo aos mesmo conceitos dos questionários originais, o que vai garantir melhor apreciação da extensão em que os serviços de reabilitação infantil brasileiros são centrados na família.

3. Leff PT, Walizer EH. Building the healing partnership: parents, professionals, and children with chronic illnesses and disabilities. J Pediatric Psychol. 1993;18(6):791-2. doi: 10.1093/jpepsy/18.6.791.

4. Salebey D. The strengths perspective in social work practice. White Plains. 1992;41(3):296-305. Doi: 10.1093/ sw/41.3.296. 
5. Fewell RR, Vadasy PF. Measurement issues in studies of efficacy. Top Early Child Spec. 1987;7(2):85-96. doi: $10.1177 / 027112148700700209$.

6. King SM, Rosenbaum PL, King GA. Family-centered service for children with cerebral palsy and their families: a review of the literature. Semin Pediatr Neurol. 2004;11(1):78-86. doi: 10.1016/j.spen.2004.01.009.

7. Pfeiffer D. Too late, too little, or both? Disabil Rehabil. 2002;24(1):985-6. doi: 10.1080/09638210152049.

8. King SM, Rosenbaum PL, King GA. Parents 'perceptions of caregiving: development and validation of a measure of processes. Dev Med Child Neurol. 1996;38(9):757-72. doi: 10.1111/j.1469-8749.1996.tb15110.x.

9. Siebes RC, Nijhuis BJ, Boonstra AM, Ketelaar M, Wijnroks L, Reinders- Messelink HA, et al. A family-specific use of the Measure of Processes of Care for Service Providers (MPOC-SP). Clin Rehabil. 2007;22(3):242-51. doi: 10.1177/0269215507081568.

10. Mcconachie H, Logan S. Validation of the measure of processes of care for use when there is no Child Development
Centre. Child Care Health Dev. 2003;29(1):35-45. doi: 10.1046/j.1365-2214.2003.00314.x.

11. King SM, Rosenbaum PL, King G. Evaluating health service delivery to children with chronic conditions and their families: Development of a Refined Measure of Processes of Care (MPOC-20). Children's Health Care. 2004;33(1):35-57. doi: 10.1207/s15326888chc3301_3.

12. CanChild. Measure of processes of care [cited 2016 Dec 05]. Available from: https://www.canchild.ca/en/resources/ 47-measure-of-processes-of-care.

13. Coster WJ, Mancini MC. Recomendações para a tradução e adaptação transcultural de instrumentos para a pesquisa e a prática em Terapia Ocupacional. Rev Ter Ocup Univ São Paulo. 2015;26(1):50-7. doi: 10.11606/issn.2238-6149.

14. Beatty PC, Willis GB. Research synthesis: the practice of cognitive interviewing. Public Opin Q. 2007;71(2):287-311. doi: $10.1093 / \mathrm{poq} / \mathrm{nfm} 006$.

15. Carvalho SR. Os múltiplos sentidos da categoria "empowerment" no projeto de promoção à saúde. Cad Saúde Pública. 2004;20(4):1088-95. doi: 10.1590/ S0102-311X2004000400024.

Recebido em: 20.12.17

Aceito em: 04.04.18 